\title{
Dreifachkombination schädigt die Niere
}

Fragestellung: Ist die gleichzeitige Einnahme von NSAR mit Diuretika und/oder RAS-Blocker mit einer erhöhten Rate akuten Nierenversagens assoziiert?

Hintergrund: Im Alltag von besonders großer Bedeutung sind Interaktionen von nichtsteroidalen Antirheumatika (NSAR) mit Diuretika und RAS-Blockern.

Patienten und Methodik: In der retrospektiven Kohortenstudie mit geschachtelter Fall-Kontrolle-Analyse wurden 487372 Fälle mit antihypertensiver Medikation (UK Clinical Practice Research Datalink/Hospital Episodes Statistics database) ausgewertet. Die Rate stationärer Krankenausaufnahmen wegen akuter Nierenschädigung bei Einnahme von NSAR + Diuretika, NSAR + RAS-Blocker (ACE-Hemmer oder AT1-Blocker) oder NSAR + Diuretika + RAS-Blocker im Verhältnis zur Rate bei Einnahme von Diuretika, RAS-Blocker oder beidem wurde bestimmt. In der mittleren Beobachtungszeit von 5,9 Jahren wurden 2215 Fälle akuter Nierenschädigung registriert.

Ergebnisse: Die Kombination eines NSAR mit einem Diuretikum oder einem RAS-Blocker allein beinhaltet kein signifikantes Risiko einer akuten Nierenschädigung. Hingegen ist die Dreifachkombination eines Diuretikums, eines RAS-Blockers

Lapi F, Azoulay L, Yin H et al. Concurrent use of diuretics, angiotensin converting enzyme inhibitors, and angiotensin receptor blockers with non-steroidal anti-inflammatory drugs and risk of acute kidney injury: nested case-control study. BMJ 2013; 346:e8525. und eines NSAR mit einem signifikanten Risiko der akuten Nierenschädigung assoziiert (Abb. 1A). Eine weitere Analyse ergab, dass das Risiko binnen der ersten 30 Einnahmetage am höchsten ist (Abb. 1B). Wird aber diese Kombination schon seit längerem eingenommen, ist das Risiko, dass noch
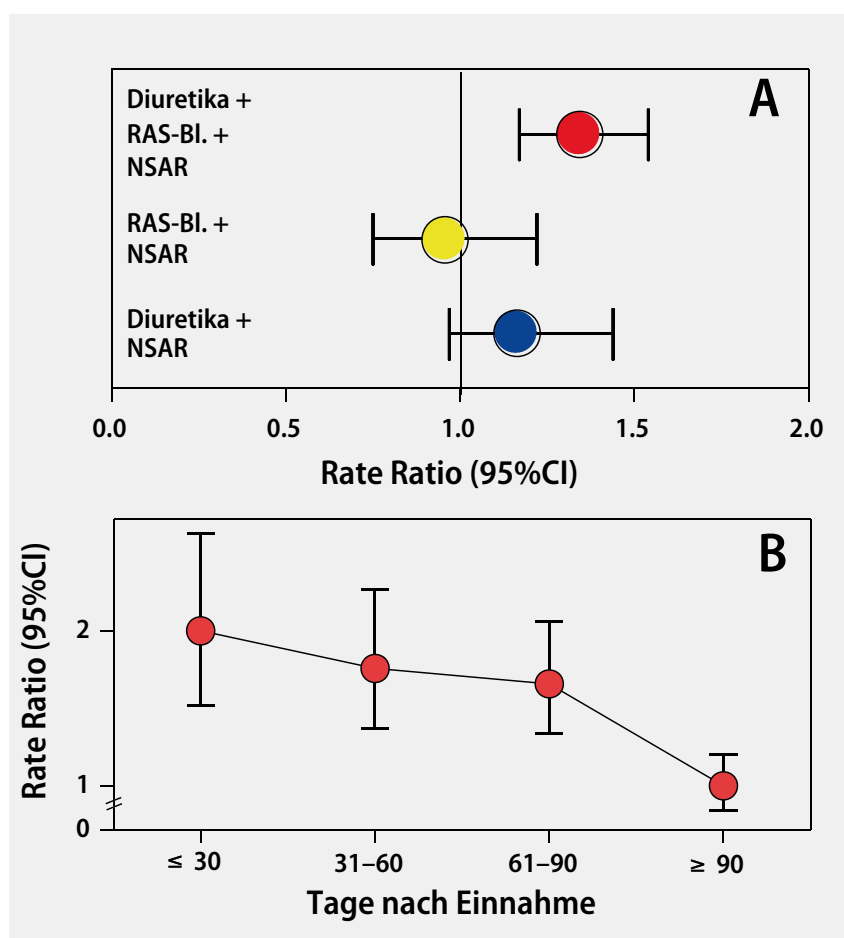

1A: Verhältnis der Rate (Rate Ratio) akuter Nierenschädigung bei Einnahme von NSAR mit Diuretika, mit RAS-Blocker oder mit beidem vs. der Einnahme von Diuretika und/oder RAS-Blockern allein. $1 \mathrm{~B}$ 1 B: Rate akuter Nierenschädigung in Abhängigkeit von der Dauer der Einnahme einer Dreifachkombination von Diuretikum, RASBlocker und NSAR.

im späteren Verlauf eine akute Nierenschädigung eintritt, nicht signifikant erhöht.

\section{-Kommentar von Prof. Dr. med. Walter Zidek}

\section{Patienten vor Risiken warnen}

Die Studie an einer großen Patientenzahl bestätigt die klinische Erfahrung: Der Dreifachkombination NSAR + Diuretikum + RAS-Blocker liegt oft eine akute Nierenschädigung zugrunde. Patienten mit vorbekannter Nierenschädigung wurden nicht berücksichtigt. Es ist anzunehmen, dass bei diesen Patienten das Risiko noch höher liegt. Diese Wechselwirkung ist praktisch von besonderer Bedeutung. Denn viele vor allem ältere Patienten erhalten wegen Hypertonie oder Herzinsuffizienz einen RAS-Blocker und ein Diuretikum und nehmen häufig mit oder ohne Wissen ihres Hausarztes zusätzlich NSAR ein. Degenerative Wirbelsäulen- oder Gelenksprobleme sind in der Altersgruppe nicht selten und meist Ursache der begleitenden NSAR-Einnahme. Diese Patienten sollten explizit vor den Risiken dieser Dreifachkombination gewarnt werden. Umgekehrt

sollte bei akuter Verschlechterung der Nierenfunktion ohne offenkundige Ursache anamnestisch vor allem nach dieser Risikokonstellation gefahndet werden.

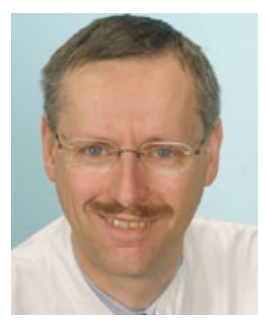

Prof. Dr. med. Walter Zidek

Med. Klinik IV, Charité Universitätsmedizin Berlin 